\title{
MAQUINAR ACCIONES \\ (A propósito del peso de las razones y de la levedad de las necesidades)
}

\author{
Manuel Cruz \\ (Universidad de Barcelona)
}

\section{A) Breve preámbulo: Ia tensión hacia el objeto}

No le corresponde, ciertamente, a la filosofia analitica el monopolio sobre el tema de la acción, aunque tal vez sí el mérito de haber sido, de entre las tradiciones filosóficas dominantes en este siglo, la que con más atención, detenimiento y sistematicidad to ha abordado. El mérito tiene sus contrapartidas: el tratamiento a que ha sometido el asunto ha sido el esperable en un pensamiento que hace bandera del rigor, la precisión y la cientificidad. Conviene empezar advirtiendo estas cosas no ya sólo para disponer psicológicamente de manera adecuada a la recepción de este mensaje, sino, lo que es mucho más importante, para disponer teóricamente para ciertas propuestas. Que tal vez no sean las más ajustadas a estos tiempos en los que, en múltiples foros, se le suele reclamar al conferenciante amenidad, cuando no directamente diversión. A este respecto me siento moralmente obligado a hacer una advertencia: las cuestiones que voy a abordar son francamente aburridas. Lo que ocurre es que, del mismo modo que casi todos estamos dispuestos a conceder que con frecuencia en los medios académicos la tediosa erudición es la excusa para abordar temas de escaso interés para los más, deberiamos aceptar que, casi con la misma frecuencia, las presuntas brillanteces y originalidades de muclios de los conferenciantes más celebrados en otros medios esconden una profunda insustancialidad.

Personalmente sólo me atrevo a defender - pero, eso sí, muy enfáticamente- la importancia teórica de los problemas a que me voy a referir y la utilidad que, para cualquier discurso que pretende hacer inteligibles las acciones humanas, tiene su enfoque.' Del cual voy a retener lo que de alguna manera constituye un desarrollo del viejo contencioso mente-cuerpo (paradigmáticamente formulado en esta tradición por Gilbert Ryle en su ya clásica obra El concepto de (o mental), a saber, el debate entre razones y deseos. En ese debate - considérenlo si lo desean como una segunda advertencia- me alinearé de modo decidido junto a las primeras. Entiendo que los agentes actúan en lo fundamental movidos por razones. Lo que no me impedirá, como es obvio, constatar que las razones asumidas incorporan o incluyen una deteminada tensión lacia su objeto o, si se prefiere, una especifica dosis de deseo. ${ }^{2} \mathrm{Al}$ hacerlas suyas, el agente las pone en contacto, en relación intima, con el resto de determinaciones que le constituyen en cuanto agente. Una razón no asumida y, en esa misma medida, no cargada de deseo no seria, en el sentido que propondré aquí, un motivo (está claro: porque no movería a nada), sino, a lo sumo, uлa creencia y ésta por si sola es algo en principio inerte. Parafraseando a Bentham (Principles

1 He desarollado inás extensamente los puntos de vista que se plantcan aquí en mi libro ¿A quien pertenece lo ocurrido?, Madrid, Taurus, 1995.

2 Respecto al deseo ticne escrito Wittgenstein: “El deseo es una actitud del espiritu, del alma, lacia un objeto". "El deseo es un estado mental que se refiere a un abjeto'. Con el fin de lacer esto más inteligible pensemos tal vez en el anhelo y en que el objeto de nuestro anhelo está ante nuestros ojos y miramos hacia él con ansia. Si no está ante nosotros, tal vez haga sus veces su imagen, y si no hay imagen, una representación. $Y$ el deseo es, pues, una actitud del alma hacia una representación. Pero en realidad siempre pensamos en la actitud del cutrpo hacia un objeto. La actitud del alma hacia la representación es precisamente lo que se podria expresar en uma pintura: el alma del hombre tendiendo hacia la imagen (una imagen real) de un objeto con gesto anhe!ante", Remaks on the Philosoply of Psichologn' (Oxford, Basil Blackivell, 1980), vol.1, \#275. 
of Morals and Legislation) cabria decir que la creencia de que la comisión de una acción favorecerá un determinado fin es condición necesaria de tener un motivo, pero no suficiente. Resulta ciertamente dificil ser rotundo $y$, mucho menos, resolutivo en este punto, (pero por el momento se trata de empezar a hablar: de proporcionarles una inicial ubicación en el interior de esta problemática).

Lo que se intentará plantear en lo sucesivo es una sospecha, de mucho más calado, referida a toda una manera de abordar la importancia del deseo a la hora de hacer comprensible el obrar humano. En esta perspectiva, lo que importa antes que nada es resaltar que la inclusión del deseo en el seno de las razones no implica un deslizamiento hacia una posición subjetivista en materia práctica. El deslizamiento (por lo demás harto frecuente ${ }^{3}$ ), cuando se produce es en buena medida como resultado de un doble supuesto no compartido aqui: I) el de que los descos pertenecen al ámbito de lo absolutamente privado y, por tanto, no son controlables de manera intersubjetiva, y 2) el de que motivos y razones deben ser pensados por scparado. Algo se dirá enseguida respecto al primero, mientras que por lo que hace al segundo remite a una problemática, en buena medida técnica, que procuraré soslayar, no sin decir que mi opción es Ia identificación entre ambos]. Pero una cosa conviene dejar clara desde el primer momento: a diferencia de lo que han planteado otros autores - como, por ejemplo, Grice, quien ha sostenido que las razones para actuar son independientes de los deseos-para mi las fórmulas no hay razón sin deseo y no hay motivo sin deseo me parecen por un igual válidas, precisamente porque las considero intercambiables.

\section{B) La posición: deseos y razones}

Alguien podría argumentar quc, en rigor, el deslizamiento hacia una posición subjetivista es una consecuencia lógica de atribuirle al agente potestad sobre las razones. Hay subjetivismo - se nos podria reprochar- porque, al hablar de las razones del agente como sus razones, el requisito del sus términos comportándose como un obstáculo insalvable por parte del espectador para acceder al sentido de la acción ajena. Pero tanto este subjetivismo como la idealización del agente son peligros teóricos evitables. Es aqui donde interviene una insistencia de Stephen Toulmin que conviene recordar. Para que de una acción se pueda sostener que ha sido llevada a cabo 'por ciertas razones' ha de pertenecer al tipo de acciones que aprendemos a realizar. 'Por razones' equivale en definitiva a evaluar las acciones, y ello es posible exclusivamente en relación con ciertas normas y criterios, y mediante unos 'modos racionales' que nos son inculcados a través de la educación y la experiencia. (Comentario al paso: los valores o valoraciones que permiten establecer la diferencia entre motivos y causas no son, a partir de esto, ni la instancia última, ni una instancia inefable acerca de cuya naturaleza resulte imposible enunciar nada. Ahora vemos que el momento de la evaluación se identifica con el momento en que hacemos uso de los procederes aprendidos.)

Asi, pues, nadie podría afirmar desde este enfoque algo parecido a "sobre razones no hay nada escrito" o defender que el peso de las consideraciones es un asunto rigurosamente privado. Detcrminados aspectos o consideraciones sobre una situación tienen peso debido a que el agente en cuestión ha aprendido a reconocer su relevancia para los procederes deliberativos en los que se halla ocupado. El peso es algo que se adquiere en el transcurso de la cxpcriencia y la educación ("y sólo entonces", anadiría quien estuvicra obsesionado por despejar cualquier

3 Con matices, podemos considerar representantes de esta posición a autores como Gilbert Harman, Bernard Williams o la misma Philippa Foot. 
sombra de idealismo en este planteamiento). No es ahí, por tanto, en ese momento imaginario de decidirse por unas razones, donde puede localizarse un hiato o salto en algún vacio gnoseológico. Es otro género de decisiones el que le plantea problemas al conocimiento. Sentado to cual, no queda más remedio que reconocer la insuficiencia de tales afirmaciones, esto es, su carácter meramente programático. No basta con la simple constatación acerca de dónde se halla el origen de este orden de procedimientos. Conviene hacerla, sobre todo para marcar las distancias respecto a los equivocos propiciados por los psicologismos más o menos esencialistas, y por algún que otro metafisico residual, pero, cumplimentada la tarea, resta pendiente el entrar en el capitulo de la naturaleza y estructura de dichos procedimientos.

\section{C) Los desarrollos: a propósito de las necesidades}

Nada de lo anterior entra en contradicción con aquella "especifica dosis de deseo", atribuida a las razones al terminar el breve preámbulo. A no ser que se entienda deseo en términos de fierza de la naturaleza, absolutamente ajena a toda consideración contextual, e incapaz de encontrar forma alguna de articulación con lo racional. Este uso es, ciertamente, frecuente. $Y$ tiene poco de extrafto que asi sea. Los argumentos que lo utilizan muestran un carácter aparentemente evidente, en parte resultado de que el deseo asi entendido se diría allegable al concepto de necesidad. ${ }^{4}$ Este último, por supuesto, está lejos de ser un concepto univoco. Pero por el momento bastará a nuestro propósito con definir las necesidades como disposiciones que urgen ciertas satisfacciones de bienestar físico, psicológico o moral para poder proseguir esta argumentación sin excesivas distracciones. La asociación deseo-necesidad proporciona al primero una cobertura naturalista que parece colocarlo de salida al margen de toda discusión, como un dato de heclio con el que no hubiera mas remedio que operar. Porque si el deseo participa de las determinaciones de la necesidad, entonces en su satisfacción parece hallarse en juego una dimensión estructural del agente. ${ }^{5}$ Ahora bien, el carácter cuasinatural atribuido al deseo es, en el fondo, consecuencia directa del modo en que toda la concepción de la epistemología empirica de tipo ilustrado (que está en la base de toda nuestra tradición cultural y, en concreto, en la de las ciencias sociales) ha tratado el tema de la naturaleza humana. Como ha selhalado Marshall Sahlins, ${ }^{6}$ el concepto de hombre que en aquélla aparece tiene como determinación fundamental la de ser un centro de necesidades en relación con los objetos susceptibles de dar placer o dolor, en una situación caracterizada por la escasez. En este contexto se va afirmando

4 Salvador Giner se refirió a esta identificación en la ciencia social en su trabajo "Aproximación critica a la lógica situacional", Madrid, Cuadernos Económicos de $/ C E, n^{\circ} 3-4,1977$, especialmente pg. 117 y ss. Existe aún sin publicar una versión actualizada de este texto que tuve ocasión de escuchar en Santa Cruz de Tenerife en marzo de 1995 con motivo de la participación del autor en el seminario de la UIMP “Acción humana y ciencias sociales: los debates abiertos".

5 Pensemos. por ejemplo, en la definición que Ch.Bay ha propuesto de las necesidades como tendencias del componamiento cuya frustración o cuya negación continuada da lugar a respuestas patológicas ("Needs, Wants and Political Legitymacy". Canadion Jourmal of Political Science, vol.1, 1968, pags.241-60) o en lo afirmado por A.H.Maslow: "un hombre al que se frustran alguna de sus necesidades básicas puede ser considerado como un enfermo 0 at menos, como algo inferior a un ser humano completo" (Mlotivation and Personalin., New York, Harper, 1954, pg.57.)

6 Marshall Salılins, "Scienza sociale in Occidente e senso tragico dell'imperfettibilita umana" en Rassegna Italiana di Sociologia, 27, $\pi^{\circ} 4,1986$, pgs.505.531. Quizá termine de clarificar el punto de visia de este autor recordar algo que la escrito a propósito de las lej'es de la naturaleza: “ $A$ pesar de toda su facticidad y su objetividad, las leyes naturales son al orden cultural lo que lo abstracto a lo concreto, el dominio de lo posible al dominio de to necesario, las potencialidades a la realización, la superviviencia a la existencia presente". en $A u$ coenr des sociétés, Paris, Gallimard, 1980, pg.260. 
la concepción estructuralista y funcionalista propia del homo oeconomicus occidentalis, que es tambièn en definitiva la imagen de la sociedad como mercado.

La trascendencia de estas afirmaciones se hace evidente cuando establecemos la comparación con culturas diferentes a la nuestra, que no parten de las necesidades del individuo y del imperativo de su satisfacción como imperativo indiscutible de la sociedad. Se comprueba entonces algo que sabiamos de antiguo, y es que la acción humana tiene siempre un significado simbólico que está en relación con el mundo interno del agente y que no puede ser considerado como un dato de partida. Si nos empeñamos en atribuirle inteligencia a los animales, habrá que decir que la suya es una inteligencia cautiva, porque una rutina biológica determina sus comportamientos: el animal repite monótonamente una técnica heredada, mientras que el hombre crea nuevas técnicas y somete su obra a planes elegidos por él mismo.

De esta forma, la acción humana rompe el continuo, caracteristico del mundo animal, entre el comportamiento manifiesto y su significado. Efectivamente, "el hombre es el ser que puede decir no", como señaló Scheler, y de esta facultad, que interrumpe la inmediatez y funda un régimen de mediación simbólica, se deriva tanto la inseguridad y debilidad del sujeto huma. no respecto a los animales a las que se ha referido Gehlen ${ }^{7}$ como el carácter abierto de su acción. El acto de comer por parte de un animal sólo puede responder a la satisfacción de una necesidad biológica, mientras que en el caso del hombre ese mismo acto puede ser efectuado por razones rituales, de prestigio, etc. ${ }^{8}$ Conviene dejar como minimo apuntado el alcance de esta interrupción. La mencionada diferencia en el sentido de los actos permite extraer una conclusión sobre el global comportamiento de la especie, sobre esa especifica temporalidad que funda la teleologia humana. Como ha sido señalado, la diferencia básica entre la conducta orientada a fines y la selección natural es que en ésta una mutación desfavorable, que implique una desventaja presente para su portador, es sancionada inmediatamente y no prepara una situación mejor en lo sucesivo, mientras que aquélla está en condiciones de asumir una consecuencia inmediatamente negativa o inconveniente en aras de los objetivos propuestos. El carácter abierto de la acción es la condición de posibilidad de nuestra idea de futuro.

La indeterminación es irreversible, en tanto en cuanto es el resultado de un rasgo constitutivo del ser humano. Lo que significa, a los efectos de la presente exposición, que para la sociedad el referente necesidades naturales es un referente definitivamente perdido. El asunto, en consecuencia, va más allá de un relativismo en la satisfacción de las necesidades que dejara intacto el contenido de éstas, ${ }^{9}$ al estilo del que parecia sugerir Marx cuando escribia: "el hambre es hambre, pero el hambre que se satisface con came guisada, comida con cuchillo y tenedor, es un hambre muy distinta del que devora carne cruda con ayuda de manos, uñas y dientes".10

7 Vid. Arrold Gehlen, El hombre. Su noturaleza y su lugar en el mundo (Salamanca, Sigueme, 1987), asi como su Antropologia filosófica. Del encuentro y descubrimiento del hombre por si mismo (Burcelonu, Paidós. 1993).

8 El hombre, par decirlo a la manera de José Antonio Marina, es un animal de lejanias: se distancia de las cosas, de los otros y hasta de si mismo. "Por eso come sin hambre, bebe sin sed, mata a los miembros de su especie e incluso se suicida" (vid. su Teoria de la inteligencia creadora, Barcelona, Anagrama, 1993, pg.20).

9 Como muestra de los intentos de determinar las necesidades clasificándolos de acuerdo con sus correspondientes satisfacciones cabe citar el listado de necesidades presentado por Y.Fridman en "About implicit limitation on satisfiers" o la tipologia propuesta por C. Mallman en "Society, Needs and Rights: A Systemic Approach" (ambos en Katrin Lederer, comp., Human Needs. A Contribution to she Current Debate, Cambridge (Mass.) y Konigstein, ???,1980, 40-41 y 155).

10 K.Marx, Elementos fandamentales para la critica de la economia politica (borrador) 1857-1858, Madrid, Siglo XX1 de Espana editores, $2^{2}$ ed.: 1972, pg.12. 
Ahora vemos que la premisa como tal ("el hambre es hambre") es lo que debe empezar siendo revisado. Los indios canadienses que analiza Sahlins siguiendo el testimonio de los misioneros jesuitas del siglo xvil controlaban severamente el estimulo del hambre por considerarlo un elemento potencialmente peligroso para la cohesión social. Actitudes que parecen inscritas en el corazón mismo de nuestra racionalidad, como la búsqueda del propio bienestar por encima de todo (ese egoismo benéfico que algunos se esfuerzan por teorizar ${ }^{11}$ ), eran juzgadas en aquella sociedad como manifestaciones patológicas, auténticos accesos de locura. Traducido a nuestro lenguaje, se diria que los indios canadienses valoraban las necesidades humanas no como el fundamento natural de la vida social, sino como lo que efectivamente son: construcciones sociales. Existe, claro está, una base biológica para ellas, unos elementos que pudiéramos convenir en denominar naturales, pero que nunca se dan tal cual, sino mediados simbólicamente. El contexto socio-cultural no es el envoltorio accidental y superfluo de las necesidades humanas. Es precisamente el entramado que les proporciona su condición de tales.

Esta afirmación, cómo no, admite múltiples matizaciones, pero es dudoso que ninguna de ellas afecte a la sustancia del argumento. Tomemos como ejemplo el modo en que Mario Bunge ha propuesto teorizar el tema de las necesidades básicas. ${ }^{12}$ De acuerdo con su tipificación, "llamamos a $x$ (i) una necesidad primaria de $b$ bajo $c$ si y sólo si la satisfacción de $x$ es necesaria para que $b$ se mantenga con vida bajo $c$ en cualquier sociedad; (ii) una necesidad secundaria de $b$ bajo $c$ si y sólo si la satisfacción de $x$ es necesaria para $b$ para conservar o recuperar la salud bajo $c$ en la sociedad particular de $b$; una necesidad básica si y sólo si $x$ es una necesidad primaria o secundaria".13 Pero si la satisfacción de las necesidades primarias es una cuestión de vida o muerte y la de las necesidades secundarias, de salud o enfermedad, ¿cómo considerar lo que está en juego en la satisfacción del conjunto de las necesidades bảsicas? Para Bunge, cuando todas ístas se encuentran satisfechas, el ser humano se halla en situación de bienestar, estado que él califica de "estado biopsicológico objetivo". A los efectos de nuestro interés, el rótulo sugerido tiene cuanto menos la vintud de mostrar la doble dimensión que en este asunto aparece involucrada. $Y$ es que los enunciados sobre necesidades son enunciados relativos a dos marcos de referencia. El primero es el de las leyes naturales que establecen una relación causal entre la satisfacción de las necesidades básicas y el bienestar de las personas, y el segundo es el de la evaluación que las personas establecen con respecto a su bienestar. Uno aporta tel elemento de objetividad, el otro, el ingrediente normativo (por el cual las personas califican de buena la satisfacción de las necesidades básicas y sostienen, en consecuencia, que debe producirse dicha satisfacción).

Por lo que estamos viendo, da Ja impresión de que la estrategia de intentar allegar deseo a necesidad puede jugarle malas pasadas a quien la defienda con el propósito de reforzar el rasgo naturalista del primero. Porque si el deseo se deja revestir con las determinaciones de la necesidad primaria, entonces to que parece ganarse por el lado de la naturaleza, se pierde por el lado de lo humano: se desvanece absolutamente la pretensión de resguardar a aquél en el

11 Asi, Von Mises y Hayek han sostenido que el egoismo es conducta natural en el hombre, en el sentido de conducta normal y racional. El segundo, que habia defendido la hipótesis general de la constitución natural altruista de la especie humana, modula la afirmación en el sentido de que el egoismo universal seria la única posibilidad de eficiencia del "gran grupo". A este tema ha hecho referencia Antoni Doménech en la conclusión de su libro De la ética a la politica, Barcelona, Critica, 1989, especialmente pp. 345-346.

12 M. Bunge, Treatise on Basic Philosophy, vol.8, The Good and the Right, Dordrecht/Boston/Lancaster, D. Reidel Publishing Company, 1989.

13 Ibidem, pg. 35 . 
ámbito de lo privado. Como acabamos de señalar, precisamente de la objetividad de la necesidad se desprende la afirmación máximamente universal según la cual todas las personas son iguales con respecto a la necesidad de satisfacer sus necesidades básicas. Por tanto, la única privacidad aquí admisible seria semejante a la contenida en afirmaciones triviales del tipo "mi hambre es mia", donde no se alcanza a ver el beneficio teórico que se obtiene de tan obvia constatación espacio-temporal.

Por supuesto que quien estuviera empenado en enfatizar el aspecto naturalista de este asunto todavía podría argumentar que la dimensión contextual de las necesidades no impide que el impulso a su satisfacción sea vivido por los agentes particulares con la misma urgencia que si fueran rigurosamente naturales. Pero este desplazamiento implica rebajar de manera considerable la potencia de los argumentos, al margen de confundir el doble plano que se ha distinguido. El hambre es una cuestión de vida o muerte para el hombre (como para cualquier otra especie animal, por lo demás), pero lo que esta afirmación exactamente significa es que en última instancia lo que se dirime en su satisfacción es la supervivencia o no del individuo, no que ante sus requerimientos no haya más remedio que plegarse (de hecho, hay personas que fallecen como consecuencia de una huelga de hambre). La confusión en gran parte viene propiciada por el hecho de que la inmensa mayoria de la gente no sólo evalúa positivamente su bienestar sino que, además, exige su satisfacción. ${ }^{14}$ Pero está claro que hablar de exigencia implica situarse en un territorio nitidamente diferenciable del de la mera urgencia. ${ }^{\text {is }} \mathrm{O}$ si se prefiere enunciarlo en negativo: hacerse fuerte en la urgencia con la que los agentes viven sus procesos recuerda el estéril gesto teórico de los historicistas que reivindicaban la centralidad de las vivencias.

No es la convicción del agente lo que se encuentra en cuestión. Más aún, sin dificultad podria aceptarse que precisamente una de las diferencias fundamentales entre deseo y necesidad pasa por aquí. Mientras que tiene sentido respecto a alguna necesidad básica (por cjemplo, secundaria) decir "necesito $x$, pero puede ser que me equivoque y en realidad no lo necesite", resulta algo chocante decir "deseo $x$ pero puede ser que me equivoque y que no desee $x$ ". 16 Parece fuera de duda que la clave del asunto pasa por determinar en qué lugar se instala el agente que hace unas afirmaciones de este tenor. En el caso de la necesidad, la respuesta parece clara: la expectativa de su universalidad - todo lo limitada, histórica y contextual que se quiera: enseguida se aludirá a esta cuestión - permite la discusión racional acerca del número e importancia de las mismas. (No otro, en suma, es el debate acerca de la justificación moral del paternalismo: 17 qué hacer cuando nos encontramos en la situación de que alguien —un incompetente básico, en la terminologia de este debate- no desea la satisfacción de $x$ porque no sabe que $x$ es una necesidad básica. ${ }^{18}$ )

14 No son pocos los autores que han inferido, explicita o implicitamente, de la existencia de ciertas necesidades el derecho a su satisfacción ( $y$ que, podriamos aladir, cuando es interiorizado por los agentes en clave de urgencia puede dar lugar a los problemas que estamos viendo). Ademís de la mayor parte de los colaboradores del ya citado Human Needs, podriamos mencionar el libro de David Braybooke Meeting Needs (Princeton, 1987) o el de Alan Gewvirth Reason and Morality (Chicago y Londres. The University of Chicago Press, 1978).

is Vid. T.M.Scanlon, "Preference and Urgency", Journal of Philosophy, 72 (1975), 655.669.

16 Emesto Garzón Valdés sa ha referido a esto en el trabajo "Necesidades básicas, deseos legitimos y legitimidad politica en la concepción ética de Mario Bunge", incluido en su libro Derecho, érica y politica, Madrid, Centro de Estudios Constitucionales, 1993, pags.417-435.

17 Vid. E.Garzón Valdés, "Es éticamente justificable el patemalismo juridico", Dara, 5, 1988, pags.155-173.

18 Gerald Dworkin ha propuesto la siguiente definición: "Por patemalismo se entiende una interferencia en la litertad de acción de otra persona, justificada exclusivamente por el bienestar, necesidades, intereses, felicidad, 
Parece justificado, por tanto, afirmar que el empeño en convertir al deseo en una instancia privada y de obligado cumplimiento termina por desarrollar unas consecuencias teóricas de dificil aceptación, en gran parte como resultado de la presencia en este supuesto de un doble emparejamiento natural/necesario e histórico-social/libre que a estas alturas se ha revelado del todo inútil. Alhora bien, será mejor advertir que todo ello no debiera interpretarse en el sentido de que no haya vínculo alguno entre las dos categorias. La critica esbozada ha ido en la dirección, bien especifica, de rechazar la asimilación o subsunción interesada de una en otra. Pero es posible otro planteamiento que, partiendo de una diferente concepción de las necesidades, proporcione precisamente una clave para la ponderación de los deseos que permita escapar de los callejones sin salida que estamos comentando. Esta via alternativa pasaria ante todo por ила reconsideración de aquella tipificación antes presentada (entre necesidades primarias y secundarias), de la cual ahora podemos empezar a sospechar que, preocupada por encontrarle un fundamento objetivo a las categorias, pasaba demasiado deprisa por encima de algunos problemas de definición que no conviene soslayar.

Ante todo, se hace preciso recordar que el propio concepto de necesidad es un concepto condicional, extremo éste que a menudo los objetivistas tienden a poner en sordina. Necesitar algo es necesitar algo para otra cosa. La afirmación "a necesita $x$ " siempre admite la pregunta "ipara qué?", de tal manera que lo propio sería decir que una descripción completa de la necesidad debe adoptar la forma "a necesita $x$ para $z "{ }^{19}$ Inevitablemente esto significa dejar la puerta abierta al interrogante " $¿ y$ para qué a necesita z?" El desplazamiento en el énfasis no viene exento de consecuencias. Por lo pronto implica que el hecho de que $x$ sea necesario para $z$ no dice nada por si sólo para la realización de $x$ : para que pueda hacerlo hay que presuponer que el agente a tiene una razón para intentar conseguir $z .^{20} \mathrm{~A}$ partir de aqui se puede insistir en el papel derivado que juega el concepto de necesidad en la justificación de la acción (puede ser usado en conjunción con principios justificativos de cualquier clase, pero no como una justificación independiente ${ }^{21}$ ). O bien se puede apuntar hacia una nueva categorización de las necesidades que recoja los matices que se están sen̉alando.

Con otras palabras: si nos quedamos en la idea de que la satisfacción de una necesidad tiene una función instrumental para la obtención de algún fin, la contingencia de ese fin determinará la correspondiente contingencia de la necesidad. Sólo un fin que no necesitara justificación ulterior podria entonces poner punto final a la cadena de preguntas acerca de la presunta necesidad de los medios para alcanzarlo. Se desprende de ello que la distinción entre necesidades pasaría a ser reformulada, tal y como ha propuesto David Wiggins ${ }^{22}$ ( $y$, en

valores, de la persona coercionada", beneficios todos ellos, habria que recalcar, que no son considerados como tales por esa persona cuyo bien se persigue (G.Dworkin,"Paternalism" en R.Sartorius, ed., Paternalism. Minneapolis, University of Minnesota Press, 1983, pag.19). Otras perspectivas relevantes respecto a este tema son las presentadas por Gert y Culver en su trabajo "Paternalism Belavior" (Philosoply and Public AJjairs, vol.6, $\mathrm{n}^{\circ} 1$, otono 1976, pags.45-77) y por Donal Van de Veer en su libro Paternalistic Interiention (Princeton, Princeton University Press, 1986).

19 Cfr. Alan R.White, Modal Thinking. Oxford, Blackwell, 1971, pags.105-106 y Anthony Flew, "Wants, Needs, Choices or Commands" en R.Fitzgerald (comp.), Human Needs and Politics (Sidney, Pergomon, 1973), pg. 216.

20 Para un anślisis de la implicaciones Iogicas del concepto de necesidad vid. Juan Carlos Bayón, La normati. vidad del derecho.... cit., pgs.116-127.

21 Cfr. Brian Barry, Political Argmment (London, Routledge \& Kegan Paul, 1965), pg.49.

"2 Cfr.David Wiggins, "Claims of Need" en Ted Honderich (ed.). Morality and Objectivitu. A nibute a J.L. Aackie (London, Routledge \& Kegan Paul, 1985), pags.149-202. 
su estela, también Harry Frankfurt), en términos de necesidades instrumentales y necesidades absolutas o categóricas. Estas últimas serian aquellas que están supeditadas a fines que no dependen de los deseos o preferencias de los agentes. La puntualización concreta de que para Wiggins ese universo esté compuesto por todo "aquello que se necesita para evitar daños a seres humanos"23 es, en un cierto sentido, lo de menos. Ese fin no justificado podria ser igualmente la intención de vivir o de funcionar normalmente, como ha sostenido Braybrooke, ${ }^{24}$ y poco cambiaria con ello en la lógica de la argumentación. De lo que se trata -lo que merece ser discutido- es de si se acepta que el concepto de necesidades absolutas puede designar una clase no vacía, de caracteristicas objetivas y universales, que puede desarrollar la función teórica de actuar a modo de dique de contención frente a todo relativismo $o$, por el contrario, consideramos que no hay forma de apelar a la necesidad como categoria última sin incurrir en petición de principio.

Porque, en efecto, parece cierto que apelar al daño como si su mera constatación ofreciera una justificación suficiente para ese juicio práctico de acuerdo con el cual una necesidad en cuestión debe ser satisfecha, supone hacer uso de un concepto normativo, y no puramente descriptivo, de daño 25 (a través del siguiente mecanismo: algo ha sido declarado previamente como valioso, de tal manera que quien experimenta su pérdida puede considerarse dañado, aunque posteriormente se presenta ese dano como un descubrimiento objetivo que justifica la satisfacción de la necesidad). La insistencia por parte de los autores que así razonan en el carácter empirico de las necesidades o en el aspecto descriptivo del criterio del daño no debicra hacer que apartáramos la mirada de la cuestión más importante, a saber, las conclusiones que extraen de sus premisas. Y es que, en definitiva, lo que da lugar según ellos a que ciertas necesidades queden excluidas del requisito de justificación ulterior -que merezcan la concluyente etiqueta de "categóricas" o "absolutas"- es el hecho de que su no satisfacción impida al agente la persecución de todo plan de vida. Son, si se quiere decir como antes, aquellas que podemos representar esquemáticamente con la fórmula " $a$ necesita $x$ para cualquier $z$ pensable".

Pero la cuestión de acerca de qué fines últimos podrian los hombres alcanzar un acuerdo unánime parece dificil de resolver a través de un examen empirico o histórico. No es trivial el dato de que hasta el momento no se haya podido presentar una lista definitiva de presuntas necesidades universales. Se han puesto ejemplos, eso si, recuperando la vieja distinción entre necesidad en si y forma de provisión. De un lado estaria la necesidad universal de tener acceso a los alimentos, de otro, la dieta mínima que cada individuo requiere para satisfacer dicha necesidad. El ejemplo es eficaz, qué duda cabe, pero las conclusiones que permite extraer resultan tan excesivas como poco operativas para la teoría: "no hay razón para esperar que la ciencia haya de descubrir algún dia que los seres humanos no necesitan alimentos o ejercicio o mantener su integridad fisica". ${ }^{26}$ El dato resistente es que la tarea de establecer cuáles son las necesidades humanas absolutas permanece incumplida. Y, desde luego, el incumplimiento no queda explicado apelando a la maraña de las cambiantes circunstancias sociales e históricas, asunto que queda fuera de discusión (entre otras cosas por sobradamente cono-

\footnotetext{
23 bidem, \#4 y ss.

24 Cfr.David Braybrooke, Meeting Needs, cit., pg.48 y Ruth Zimmerling. "Necesidades básicas y relativismo moral", Daxa, 7, 1990, especialmente pag.43 y ss.

25 Para un análisis del carácter objetivo de esta noción vid. G.Thomson, Needs (London, Routledge \& Kegan Paul, 1987) pags.35-63.

26 Braybrooke, op.cit., pag.52.
} 
cido27). Al fin y al cabo, si sólo fuera culpa de eso, incluso podria darse la vuelta al argumento y sostener que la pretensión de elaborar un catálogo cerrado de las necesidades implica una recaida en alguna variante del viejo modelo de naturaleza humana universal e inmutable.

Sin embargo, las sucesivas respuestas y matizaciones a las criticas planteadas a la noción de necesidad absoluta (respuestas y matizaciones del tipo: dado que las necesidades humanas son hechos empiricos, nunca podemos tener la seguridad de haber descubierto todos los hechos relevantes en un contexto determinado; las propias necesidades tienen tendencia al cambio; los valores personales y colectivos afectan directamente a la definición de necesidades y a las formas a través de las que se satisfacen; las necesidades no aparecen nunca en forma pura, fuera de un contexto social específico...) lejos de mostrar la fortaleza de la misma, han ido desvirtuando su carácter hasta dejarnos finalmente ante una noción de dudosa rentabilidad discursiva, una especie de idea reguladora para defendemos del vértigo de lo derivado. ${ }^{28}$ Probablemente lo más criticable de esta estrategia fundamentalista respecto a las necesidades sea el supuesto esencialista con el que opera y el modo en que intenta legitimarlo. La objetividad no se demuestra con argumentos formales del tipo: "ha de haberla, porque si no.....29 En realidad por ese camino lo que se consigue, paradójicamente, es desdibujar ese rasgo a base de sobrecargarlo de una responsabilidad teórica que no está en condiciones de soportar.

A no ser que se identifique objetividad con realismo - cosa que no hay por qué lacerel naufragio de su universalidad no arrastra consigo a la idea de necesidad en cuanto tal. Lo que se desprende del fracaso de intentar convertir la apelación a la necesidad en una justificación independiente no es la completa inutilidad de la categoria, sino la evidencia de que no puede operar como referencia categorial última. Pero nada impide - más aún, existen muchos razonamientos a favor - utilizarla en conexión con las categorias adecuadas. Y, como es fácil de imaginar por lo que he venido diciendo, a mi entender la conexión primordial se ha de establecer con alguna variante de la noción de persona (que bien pudiera ser sujefo o identidad personal). Revisando la noción de bienes primarios que habia presentado en su Teoria de la jusficia, Rawls ha criticado el empeño en hacer descansar una lista de bienes primarios en un determinado tipo de hechos generales ("cualequiera fines últimos que un examen empirico o histórico comprehensivo pudiera mostrar que la gente por regla general o normalmente tiene en común en todas las condiciones sociales"). Lo de ménos es si tales hechos existen, asunto en el

27 Cómo no evocar la definición del concepto de necesidad que proporciona Adam Smith justo antes de poner el famoso ejemplo de la camisa de hilo: "Por cosas necesarias entiendo no sólo las facilidades que son necesariamente indispensables para la vida, sino aquello que la costumbre def pais hace que sea indecente carecer de ellas para gentes dignas de crédito, incluso de la clase más baja [...] A todas las demás cosas Ias llamo lujo".

28 La distinción entre necesidades derivadas y no derivadas la la propuesto G.Thomson en su ya citado Needs, pags.18-19.

29 En ciento sentido, ésa es la estrategia argumentativa seguida por Len Doyal y lan Gough en su libro Teoria de Ias necesidades Mumanas (Madrid, Icaria, 1994). Los autores se proponen presentar y justificar una "icoria coherente y rigurosa de las recesidades humanas" que defina qué necesidades merecen este calificativo y por que?. con una intención muy clara. En efecto, como yu se ha señalado, si fuéramos capaces de demostrar la existencia de unas necesidades propias de todos los hombres y de realizar una descripción adecuada de las inismas, liabriamos alcanzado un criterio eficaz para evaluar la justicia de un orden sociopolitico determinado. Pero sostener, coino ellos hacen, que tales necesidades existen (y sehalan la salud fisica y la autonomia) puesto son requisitos para que los seres humanos puedan asumir su condición de personas y participar libremente en su forma de vida implica, de forma abiena, inferir el es a partir del debe (o los deseos con la realidad). 
que Rasvls parece dispuesto a transigir. Lo que importa es que la determinación de los bienes primarios sólo puede ser hecha "a la luz de una concepción de la persona humana dada de antemano". 30

Por supuesto que "de anternano" en este contexto no equivale a "desde siempre". La insoslayable dimensión dinámica y procesual de esta otra noción puede vehicularse de diferentes formas, como, por ejemplo, la presentada por Amartya Sen mediante la noción de capacidades básicas de las personas. ${ }^{31}$ Según esto, cualquier individuo se autorrealiza en la medida en que actualiza en forma plena y equilibrada sus diferentes capacidades. Demorarse en discutir dicha noción nos apartaria del objeto de nuestro discurso. El caso es que la propuesta de Sen sintoniza y refuerza la línea de argumentos que estamos presentando. Porque, como se recordarí, la critica que se hizo fué a la pretensión de que la apelación al daño constituyera una justificación suficiente para la afimación de que una deteminada necesidad debe ser satisfecha. Pero seria abusivo interpretar esta critica en el sentido de negar que las necesidades proveen razones para actuar en la forma en que se hace. Una cosa es rechazar la definición - sobre todo por el automatismo implicado en ella- que presenta Gewirth ${ }^{32}$ de los derechos humanos como "reclamaciones justificadas a la satisfacción de necesidades importantes" y otra, bien distinta, constatar que si mostramos que una determinada necesidad existe resultaría lógicamente extraño y autocontradictorio abstencrse de exigir su satisfacción. Tras todo lo planteado, pienso que estamos en condiciones de aceptar la tesis ${ }^{33}$ según la cual las necesidades, si bien no pueden ser consideradas razones concluyentes para la acción, si representan buenas razones para la misma.

A diferencia de una razón concluyente, una buena razón es aquella que exige a su vez razones evaluadoras o criterios de evaluación, a partir de los cuales sea posible preferir unas frente a otras en contextos dados. ${ }^{34}$ Con otros términos, las necesidades deben tener algün tipo de base que permita dar razones que expliquen o fundamenten su satisfacción. Es por aqui por donde debe buscarse lo especifico de la necesidad en relación a otros conceptos como el de deseo. A este respecto, se puede afirmar ya que la primera diferencia entre necesidades y descos (y la mayor fuerza argumentativa de las primeras) viene dada precisamente por su carácter objetivo, por ellas tratarse de situaciones o estados de cosas que no dependen de los fines y objetivos del sujeto. Pero, además, existe otra diferencia en función del resultado: satisfacer las necesidades evita un daino, cumplir los deseos proporciona un beneficio. Aunque tal vez en este caso resultara más esclarecedora la formulación en negativo: la privación de las necesidades

30 J.Raivls, Justicia como equidad (Madrid, Tecnos, 1986), pag.194.

31 El propio Rawls cita en ibidem, pg.195, el urabajo de Sen "Equality of What?", en S.MacMurrin (ed.), Tanner Lectures on Humant Lalues, I, Cambridge, Cambridge University Press, 1980 (reeditado en A.Sen, Choice, Welfore and Measurement, Oxford: Blackwell y Cambridge, Mass.: MIT Press, 1932). Vid. también, de este mismo autor, "Well-being, agency and freedom, the Dewey Lectures 1984", Journal of Philosoplur, 82, 1985, y Commodisies and Capabilities, Amsterdam, North-Holland, 1985.Sobre el origen en última instancia aristotélico del concepto (Polisica, Libro Ill) y su relación con las discusiones conteporaneas sobre el bienestar vid. Martha C.Nussbaum, "Nature, Function, and Capability: Aristotle on Political Distribution". Oxford Sindies on Anciemt Philosoply;, suppl.vol., 1988.

32 A.Gewirth, Reason and Moralin', cit., pag.7. Aunque es obligado matizar que la definición tiene como trasfondo la idea que este autor defiende de la naturaleza del ser humano como "agente que persigue fines", idea de la que entiende que se sigute, bajo riesgo de incurrir en autocontradicción, el derecho de todo ser humano a los bienes necesarios para perseguir algún fin. 1990.

33 Defendida por Javier de Lucas y Maria José Anón en su trabajo “Necesidades, razones, derechos", Doxa, 7.

34 Vid. N.MacCormick y Ota Weinberger, An Institutional Theory of Law. New Appraaches to Legal Positrism, Dordrecht/Boston/Lancaster, Reidel, 1986, pag.194. 
constituye un daño, la frustración de un deseo produce una ausencia de beneficio. Enunciada así, se hace evidente la valoración que permite establecer la prioridad de las necesidades sobre los deseos: es peor causar un daño que dejar de dar un beneficio.

Ni objetividad ni daño — resulta importante destacarlo - han vuelto a aparecer sin más, como si nada hubiera sido dicho. Antes bien al contrario, es su inscripción en un determinado marco teórico la que los hace ahora operativos. Así, precisamente porque no se pretende utilizar el concepto de persona para reintroducir una variante de neoesencialismo de las necesidades, puede aceptarse el reproche que a este último criterio han presentado algunos autores, ${ }^{35}$ reproche según el cual la distinción en cuanto tal entre causar un dar̃o y no dar un benefíco se debe al hecho, contingente desde el punto de vista moral, de si el individuo tenia acceso previamente al bien en cuestión —en cuyo caso su privación constituye un daño- o no lo tenia -en cuyo caso consiste en la mera negación del beneficio-. Pero de semejante premisa no se sigue como exclusiva conclusión que el principio de la prioridad de las necesidades sobre los deseos favorece el mantenimiento del statu quo. Esto puede ser verdad, pero en cualquier caso no toda la verdad. Porque, de serlo, lo seria como aplicación de un principio más general.

De ahí la reserva presentada anteriormente respecto al modo en que Bunge definia el bienestar (esa situación en la que se encuentra un ser humano cuando "están satisfechas todas sus necesidades bäsicas" ${ }^{36}$ ) como estado biopsicologico objetivo: no conseguia explicar porqué no toda privación o carencia tiene idénticas consecuencias, del mismo modo que no toda frustración de un deseo produce un perjuicio. Con otras palabras, la afirmación de Wiggins "lo que necesito no depende del pensamiento o del funcionamiento de mi cerebro [...] sino de cómo es el mundo" 37 será trivialmente verdadera o será equivoca, según que se la entienda o no a la luz de esta otra afirmación complementaria: la ausencia de bienestar o de felicidad (su correlato para los deseos) pueden ser considerados como dano o perjuicio cuando son aceptados como tales por parte de la comunidad.

No hay margen para interpretar esto, en el extremo opuesto, como un desplazamiento desde lo que alguien podia haber estimado como un cierto relativismo diacrónico inicial a un relativismo sincrónico. Se le ha cerrado el paso a tal interpretación introduciendo razones y personas. Gracias a ambos conceptos es pensable una argumentación $-\mathrm{y}$ no una mera postulación dogmática - acerca del daño que produce una determinada carencia 0 , por el contrario, acerca de la conveniencia de no satisfacer alguna ${ }^{38} \mathrm{Ha}$ cambiado, por tanto, el lugar discursivo atribuido a las necesidades. Ya no son vistas como deterninación a cumplir (o dato a constatar). Que objetividad sólo puede ser entendida como intersubjetividad desarrolla en este caso unas muy precisas consecuencias. Desaparecida definitivamente la posibilidad teórica de sustraer las necesidades al control de la exterioridad, se abre paso la conveniencia de situar el planteamiento de las mismas en el ámbito más propicio para su comprensión.

Con la mera indicación será suficiente para lo que hace al caso: introducir la racionalidad y la razonabilidad es el modo de convertir en discursiva la presencia de las necesidades. El modo a través del cual podemos acceder a la doble pregunta teórico-práctica: ¿qué queda expli-

Is Vid. Robert E.Goowin, "The Priority of Needs", en Philosophy and Phenomenological Research, $45,1985$. En idéntico sentido se pronunciaba Carlos S. Nino, quien también aludia a la crítica de Goovin, en "Autonomia y necesidades básicas", Dora, 7, 1990, pags.21-34.

36 Bunge, op.cil.,pg.44.

37 D.Wiggins, "Claims...", cit., \#3.

38 Cfr. Josl Feinberg, Social Philosophy'. New Jersey, Prentice Hall, 1979, pags.45-52. 
cado apelando a la necesidad? y ¿qué hacer frente a la reivindicación de su satisfacción? Polemizando con quienes juzgan el bienestar de una persona exclusivamente por la felicidad o la satisfacción del deseo, Sen se ha alineado con el punto de vista que estoy defendiendo: "El bienestar es, en el fondo, una cuestión de valoración".39 Pero, quede claro, al final de la valoración - y a la vista de cuantos condicionamientos históricos y sociales hagan falta - puede haber la constancia insoslayable de que para determinados hombres concretos hay un tipo de necesidades cuya satisfacción debe alcanzar el rango normativo: necesidades rigurosamente inexcusables. (No cabe negarse esta posibilidad. La inscripción de cualquier objeto en sus particulares coordenadas contextuales ha de servir para fijar las condiciones de su conocimiento, en ningún caso para pulverizarlo.)

Con todo este rodeo, la distinción inicial ha ido cobrando contenido. En efecto, los conceptos se mantienen a distancia: “a diferencia de 'desear' o 'querer' [...] 'necesitar' no es, obviamente, un verbo intencional". ${ }^{40} \mathrm{La}$ obstinación teórica por aproximarlos fracasa, como hemos visto, en lo esencial. Acaso pudiéramos concluir que las necesidades no constituyen los mejores compañeros de viaje para los deseos. 0 , con más exactitud, que para que cumplieran adecuadamente esa mera función de refuerzo haria falta olvidar lo que a las primeras les es más especifico, aquello que les permite operar, todo lo tentativamente que se quiera, como referente básico de los derechos. No elegimos nuestras necesidades, no son algo sobre lo que realicemos una acción positiva: por eso tiene sentido, a propósito de ellas, sugerir una concepción neutral con respecto al evaluado. Es esa particular objetividad, a la que ya hemos hecho suficiente referencia, la que permite instituir el lugar teórico desde el que resolver la tensión valorante-pretendientefl que se produce en el agente que extrae de la afirmación de la existencia de una necesidad, el derecho a su satisfacción. Con otras palabras, la universalidad de las necesidades no es la del concepto sino la de la acción: significa derecho a un trato igualitario.

\footnotetext{
39 Amanya Sen, Sabre ética y economia (Madrid, Alianza, 1989), pg.63. A propósito del carácter instrumental de este punto de vista, comeata el propio Sen en nota a pié de página: "esta manera de considerar el bienestar tiene poderosas implicaciones no sólo para la economia del bienestar, sino también para la evaluación dél nivel de vida, la pobreza la desigualdad, la división sexual y la justicia social". Aportaciones mis recientes a esta discusión las constituyen su trabajo "'Capability and Well-Being", asi como el de Gerald A.Colien, "Equalty of What? On Welfare, Goods, and Capabilities" (ambos en Martha C.Nussbaum and Amantya Sen,eds., The Qualiny of Life, Oxford, Clarendon Press, 1993), pags.30-53 y 9-29 respectivamente.

40 David Wiggins, "Claims...", op.cit., \#3.

41 "Entre la aserción del agente de que su libertad y bienestar son bienes necesarios y su aserción posterior o pretensión de que tiene derecho a estos bienes, existen las importantes diferencias de que en la última aserción los bienes son presentados no simplemente como valiosos o descables sino como objetos a los cuales el agente tiene derecho o que debe poseer por serles debidos y el agente se encuentra en la posicion no sólo del evaluador sino también del pretendiente", A.Gewirth, op.cit., pg.6t (subrayado,M.C.).
} 